\title{
Effects of vertebroplasty on endplate subsidence in elderly female spines
}

\author{
Srinidhi Nagaraja, PhD, Hassan K. Awada, BS, Maureen L. Dreher, PhD, John T. Bouck, MS, \\ and Shikha Gupta, PhD
}

U.S. Food and Drug Administration, Center for Devices and Radiological Health, Office of Science and Engineering Laboratories, Division of Solid and Fluid Mechanics, Silver Spring, Maryland

OBJECT The aim in this study was to quantify the effects of vertebroplasty on endplate subsidence in treated and adjacent vertebrae and their relationship to endplate thickness and underlying trabecular bone in elderly female spines.

METHODS Vertebral compression fractures were created in female cadaveric (age range 51-88 years) thoracolumbar spine segments. Specimens were placed into either the control or vertebroplasty group ( $n=9 /$ group) such that bone mineral density, trabecular microarchitecture, and age were statistically similar between groups. For the vertebroplasty group, polymethylmethacrylate bone cement was injected into the fractured vertebral body under fluoroscopy. Cyclic compression (685-1370 N sinusoid) was performed on all spine segments for 115,000 cycles. Micro-CT scans were obtained before and after cyclic loading to quantify endplate subsidence. Maximum subsidence was compared between groups in the caudal endplate of the superior adjacent vertebra $\left(\mathrm{SV}_{\text {cau }}\right)$; cranial $\left(\mathrm{TV}_{\text {cra }}\right)$ and caudal $\left(\mathrm{TV}_{\text {cau }}\right)$ endplates of the treated vertebra; and the cranial endplate of the inferior adjacent vertebra $\left(\mathrm{IV}_{\mathrm{cra}}\right)$. In addition, micro-CT images were used to quantify average endplate thickness and trabecular bone volume fraction. These parameters were then correlated with maximum endplate subsidence for each endplate.

RESULTS The maximum subsidence in $\mathrm{SV}_{\text {cau }}$ endplate for the vertebroplasty group $(0.34 \pm 0.58 \mathrm{~mm})$ was significantly $(p<0.05)$ greater than for the control group $(-0.13 \pm 0.27 \mathrm{~mm})$. Maximum subsidence in the $\mathrm{TV}_{\text {cra, }} \mathrm{TV}_{\text {cau }}$, and $\mathrm{IV}_{\text {cra }}$ endplates were greater in the vertebroplasty group, but these differences were not significant $(p>0.16)$. Increased subsidence in the vertebroplasty group manifested locally in the anterior region of the $\mathrm{SV}_{\text {cau }}$ endplate and in the posterior region of the $\mathrm{TV}_{\text {cra }}$ and $\mathrm{TV}_{\text {cau }}$ endplates $(\mathrm{p}<0.10)$. Increased subsidence was observed in thinner endplates with lower trabecular bone volume fraction for both vertebroplasty and control groups $\left(\mathrm{R}^{2}\right.$ correlation up to $\left.62 \%\right)$. In the $\mathrm{SV}_{\text {cau }}$ endplate specifically, these 2 covariates aided in understanding subsidence differences between vertebroplasty and control groups.

CONCLUSIONS Bone cement injected during vertebroplasty alters local biomechanics in elderly female spines, resulting in increased endplate disruption in treated and superior adjacent vertebrae. More specifically, bone cement increases subsidence in the posterior regions of the treated endplates and the anterior region of the superior caudal endplate. This increased subsidence may be the initial mechanism leading to subsequent compression fractures after vertebroplasty, particularly in vertebrae superior to the treated level.

http://thejns.org/doi/abs/10.3171/2014.10.SPINE14195

KEY WORDS vertebroplasty; biomechanics; trabecular bone; endplate; subsidence; micro-CT; lumbar

$\mathrm{V}$ ERTEBRAL compression fractures (VCFs) are a significant public health concern affecting approximately 1.4 million individuals worldwide. ${ }^{37}$ Due to accelerated bone loss at the onset of menopause, women in particular suffer VCFs 3 times more frequently than men. ${ }^{26}$ Osteoporosis-related VCFs are a significant health risk for elderly women as previous reports have shown that $25 \%$ of all postmenopausal women and $40 \%$ of women older than 80 years in the United States sustain at least one VCF. ${ }^{31,40}$ A common surgical treatment for VCFs is

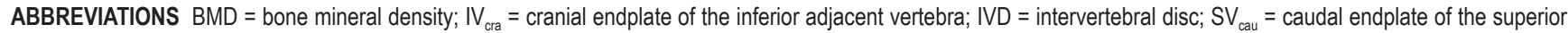
adjacent vertebra; $\mathrm{TV}_{\text {cau }}=$ caudal endplate of the treated vertebra; $\mathrm{TV}_{\text {cra }}=$ cranial endplate of the treated vertebra; $\mathrm{VB}=$ vertebral body; $\mathrm{VCF}=$ vertebral compression fracture.

SUBMITTED February 19, 2014. ACCEPTED October 30, 2014

INCLUDE WHEN CITING Published online December 19, 2014; DOI: 10.3171/2014.10.SPINE14195.

DISCLOSURE This research study was funded by a grant through the FDA's Office of Women's Health. The authors report no conflict of interest concerning the materials or methods used in this study or the findings specified in this paper. 
vertebroplasty; however, there has been considerable debate regarding its efficacy in providing pain relief when compared with conservative therapies (i.e., medications). Two multicenter, randomized trials found no beneficial effect of vertebroplasty compared with control groups in patients with painful VCFs. ${ }^{6,21}$ However, these findings have been challenged by others, ${ }^{12,13,17}$ and more recent clinical trials found that pain relief after vertebroplasty was significantly improved compared with conservative treatment..$^{27,42}$

For the patient, pain relief after vertebroplasty may only be temporary due to an increased risk of additional VCFs, potentially outweighing the benefits of this procedure. ${ }^{43}$ The biomechanical concern is that the addition of bone cement in vertebroplasty procedures negatively alters load transfer in the spine, especially in adjacent vertebrae and intervertebral discs (IVDs). Studies have shown that factors such as bone cement volume and spatial distribution inside the vertebral body (VB) are important in the occurrence of subsequent fractures. . $^{10,22,23,32}$ In addition, the stiffness of bone cement (approximately 10 times stiffer than osteoporotic vertebral bone) has been thought to act as a rigid pillar within the treated vertebra, transferring forces to IVDs and vertebrae adjacent to the original fracture. ${ }^{2,3}$ Finite element analyses have estimated that vertebroplasty increases pressure in adjacent IVDs by $19 \%$ and stresses in adjacent endplates and trabecular bone by $17 \%$ and 5\%, respectively.,36 Vertebral trabecular bone, particularly near the endplates, plays an important biomechanical role, distributing up to $85 \%$ of the applied load. ${ }^{11}$ Therefore, increased stresses in adjacent endplates and underlying trabecular bone may contribute to clinical observations of up to $25 \%$ of adjacent-level fractures in patients postvertebroplasty ${ }^{9,41}$ and onset at a significantly faster rate than nonadjacent fractures. ${ }^{43,44}$ In fact, Trout and colleagues observed endplate fractures immediately surrounding the augmented vertebra. ${ }^{45}$ Although previous clinical studies have identified endplates as an important factor in adjacent-level fractures, the amount and spatial distribution of subsidence across the endplate after vertebroplasty and its relationship with the underlying trabecular bone remain unclear. Therefore, the objective of this study was to quantify the effects of vertebroplasty on endplate subsidence and its relationship to endplate thickness and trabecular bone volume fraction in elderly female spines. We hypothesized that vertebroplasty increases the risk for subsidence to surrounding endplates, and the magnitude of this subsidence is inversely correlated to endplate thickness and trabecular bone volume fraction.

\section{Methods}

\section{Specimen Preparation}

Caucasian female cadaver spines (age range 51-88 years) were selected based on visual and radiographic examination. Donors with evidence of device implantation, scoliosis, and existing vertebral fractures were excluded. Thoracolumbar segments (T11-L3) were dissected and cleaned, leaving intact IVDs, VBs, spinous processes, pedicles, and ligaments. The T-11 and L-3 end vertebral levels of each sample were fixed in a rapidly curing epoxy
(3M) to provide flat uniform surfaces for mechanical testing. A compression fracture was induced in all specimens using a previously published method ${ }^{23}$ to simulate wedge fractures in cadavers while preserving the integrity of the vertebral endplates. Briefly, a thin transverse cut was created through the anterior half of the L-1 VB to compromise the anterior cortex and trabecular bone in this region. Compression bending was then applied in a mechanical testing system (MTS Systems Corp.) until compression reached half of the height of the L-1 VB. The L-1 vertebra was selected for treatment as it has the highest fracture incidence in the female lumbar spine. ${ }^{39}$ After the compression fracture, specimens ( $\mathrm{n}=9$ /group) were placed into a vertebroplasty group or a control group (no vertebroplasty procedure) such that age, bone mineral density (BMD), and trabecular microarchitecture were similar between groups. Cadaver ages were similar between the vertebroplasty group (78 \pm 9 years) and the control group ( $75 \pm 12$ years, $\mathrm{p}=0.50)$. Lumbar BMD determined using dualenergy x-ray absorptiometry (DEXA, Hologic) in the vertebroplasty group $\left(0.73 \pm 0.13 \mathrm{~g} / \mathrm{cm}^{2}\right)$ was not statistically different from that in the control group $(0.75 \pm 0.09 \mathrm{~g} /$ $\left.\mathrm{cm}^{2}, \mathrm{p}=0.67\right)$. In addition, T-scores for the vertebroplasty group $(-2.9 \pm 1.2)$ was similar to the control group $(-2.6$ $\pm 0.9, p=0.59)$. A summary of statistics regarding BMD, age, and trabecular microarchitecture parameters is listed in Table 1.

\section{Vertebroplasty Procedure}

Specimens in the vertebroplasty group were injected with polymethylmethacrylate bone cement (Stryker) in the fractured L-1 VB using a unilateral transpedicular approach. Under fluoroscopic guidance, an 11-gauge bone biopsy needle was advanced into the VB through the pedicle lateral to the superior articulating facet. Bone cement was confined to the anterior three-fourths of the VB based on lateral projections. ${ }^{7,21,25}$ The resulting cement fills (22\% $\pm 3 \%$ ) are similar to those used in previous studies. ${ }^{28,32,34}$ Endplate deformation or damage from the vertebroplasty procedure was not observed in these cadavers as visualized through postinjection fluoroscopy. After augmentation, specimens were allowed to cure at room temperature and then stored at $-20^{\circ} \mathrm{C}$ until testing.

\section{Cyclic Loading}

All spine segments were thawed in $0.9 \%$ saline for 4 hours prior to cyclic compression. Cyclic loading (685$1370 \mathrm{~N}$ sinusoid) was within the range of spinal compressive loads encountered during brisk walking. ${ }^{8}$ Testing was conducted at $2 \mathrm{~Hz}$ for 115,000 cycles (approximately 16 hours) to prevent significant degradation or changes in spinal range of motion. ${ }^{46}$ Mechanical testing (MTS Systems Corp.) was carried out at room temperature, and specimens were wrapped in saline-soaked gauze and were sprayed intermittently to maintain hydration throughout testing.

\section{Endplate Subsidence}

High-resolution micro-CT (Scanco Medical) was used to assess damage and subsidence in endplates, as well as to assess endplate thickness and underlying trabecular bone 
TABLE 1. Characteristics of the specimens in each group*

\begin{tabular}{lccccccccc}
\hline \multirow{2}{*}{ Group } & Age $(\mathrm{yrs})$ & BMD $\left(\mathrm{g} / \mathrm{cm}^{2}\right)$ & T-Score & BVF $(\%)$ & TM $(\mathrm{mg} \mathrm{HA} / \mathrm{cc})$ & Tb.Th $(\mathrm{mm})$ & Tb.Sp $(\mathrm{mm})$ & Conn.D $\left(1 / \mathrm{mm}^{3}\right)$ & DA \\
\hline Control & $75 \pm 12$ & $0.75 \pm 0.09$ & $-2.6 \pm 0.9$ & $8.4 \pm 1.1$ & $669 \pm 38$ & $0.113 \pm 0.005$ & $0.96 \pm 0.11$ & $4.2 \pm 0.8$ & $1.26 \pm 0.08$ \\
\hline Vertebroplasty & $78 \pm 9$ & $0.73 \pm 0.13$ & $-2.9 \pm 1.2$ & $8.0 \pm 1.4$ & $668 \pm 37$ & $0.113 \pm 0.005$ & $0.98 \pm 0.09$ & $4.0 \pm 1.3$ & $1.27 \pm 0.07$ \\
\hline
\end{tabular}

$\mathrm{BVF}=$ bone volume fraction; Conn. $\mathrm{D}=$ connectivity density; $\mathrm{DA}=$ degree of anisotropy; $\mathrm{TM}=$ trabecular mineralization; $\mathrm{Tb}$. Th = trabecular thickness; Tb.Sp = trabecular spacing.

* Donors were assigned into control and vertebroplasty groups to have statistically similar $(p>0.5)$ bone parameters.

in both treated (L-1) and adjacent (T-12 and L-2) vertebrae. Micro-CT imaging (0.05-mm voxel size) was conducted twice in each spine section. The first scan was obtained after compression fracture but prior to vertebroplasty and cyclic loading. Samples were rescanned at the same resolution after cyclic loading. 3D volumetric images were rendered from the scans by thresholding gray-scale images with values that discriminated between bone, marrow, and disc tissue. Pretest and posttest scans provided morphology of endplates, trabecular bone, and other vertebral structures. Endplate damage due to mechanical testing was determined by examining micro-CT images (Fig. 1).

Endplate subsidence was calculated from thresholded pre- and posttesting micro-CT images in the caudal end- plate of the superior adjacent vertebra $\left(\mathrm{SV}_{\text {cau }}\right)$; the cranial $\left(\mathrm{TV}_{\text {cra }}\right)$ and caudal $\left(\mathrm{TV}_{\text {cau }}\right)$ endplates of the treated vertebra; and the cranial endplate of the inferior adjacent vertebra $\left(\mathrm{IV}_{\text {cra }}\right)$. One sample in each group was omitted because of artifacts on the posttest scan that prevented endplate subsidence analysis. To calculate subsidence, endplates were rotated three-dimensionally (i.e., in the $\mathrm{x}, \mathrm{y}$, and $\mathrm{z}$ axes) to create a horizontal plane between the endplate's anterior rim and posterior horns. With this approach, the reference plane was kept constant between the 2 endplates to ensure consistent subsidence evaluation. Once aligned, a custom algorithm was developed to spatially calculate the depth of the endplate from the horizontal plane connecting the anterior rim and posterior horns. Endplate subsidence be-

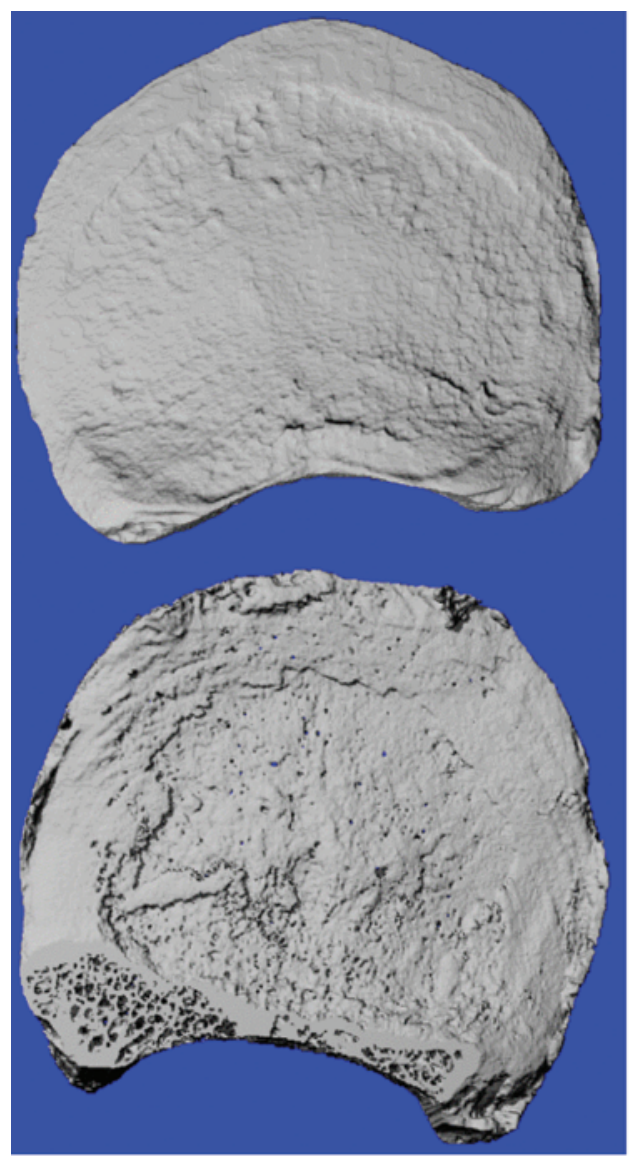

Pre-test

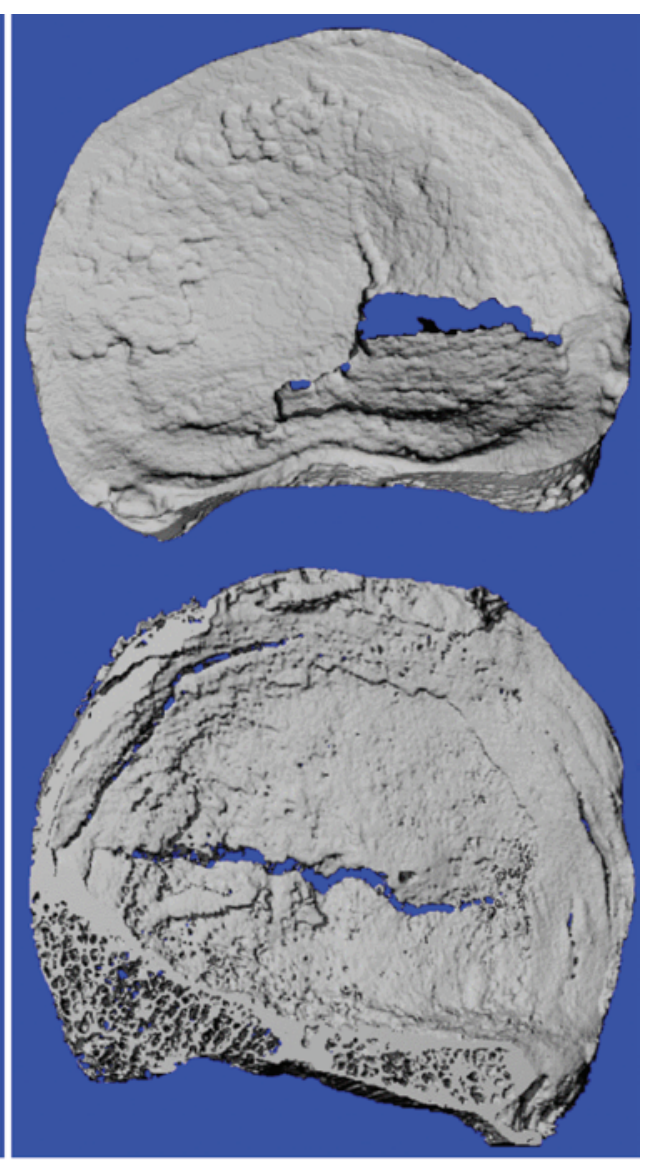

Post-test

FIG. 1. Representative micro-CT images of vertebral endplates obtained before (left) and after (right) mechanical testing. Large cracks were detected after testing, typically in the mediolateral direction. Figure is available in color online only. 
tween pre- and postmechanical testing was calculated as the difference between the maximum posttest and pretest depths. In addition, endplate subsidence was compared across the vertebral endplate in 3 spatial regions (anterior, middle, and posterior; Fig. 2).

\section{Correlation of Subsidence With Endplate Thickness and Trabecular Bone Volume Fraction}

Endplate subsidence was correlated with average endplate thickness and underlying trabecular bone from pretest micro-CT images. To accomplish this, a semiautomated method was used to extract trabecular bone approximately $2 \mathrm{~mm}$ directly beneath the endplate. First, contours were manually drawn to separate trabecular bone from the endplate and cortical shell. A threshold was then selected to segment trabecular bone from background/marrow based on density and morphological features (Fig. 3A). Similarly, endplates were segmented from the underlying trabecular bone using contours and thresholding (Fig. 3B). The resulting 3D images of the trabecular bone and endplate were used to calculate trabecular bone volume fraction and endplate thickness, respectively, based on well-established and validated methods. ${ }^{15,16,38}$ Endplate subsidence was then correlated with prevertebroplasty endplate thickness and trabecular bone volume fraction.

\section{Statistical Analysis}

All data are presented as the mean \pm SD. ANOVA analysis (Minitab, Minitab Inc.) was used to assess endplate subsidence between control and vertebroplasty groups. Tukey's pairwise comparisons were performed to determine statistical significance. All statistical tests were 2 -sided with a 0.05 significance level. Demographic characteristics, BMD, and trabecular microarchitecture were compared between the vertebroplasty and control groups using 2-sample independent t-tests. Linear regression analyses were performed to determine the correlation of observed endplate subsidence with average endplate thickness. Multiple linear regression analyses were also conducted adding trabecular bone volume fraction as a covariate to the statistical model.

\section{Results}

\section{Endplate Fractures}

Endplate fractures in adjacent VBs (T-12 and L-2) for both the control and vertebroplasty groups were not detected after mechanical testing. However, cranial endplate fractures were detected in the treated level (L-1) in both the control and vertebroplasty groups after cyclic loading. Seventy-eight percent of specimens (7 of 9) in the vertebroplasty group sustained endplate cracks compared with $44 \%$ of specimens (4 of 9) in the control group; however, this difference was not significant $(p=0.34)$. One specimen in each group had fractures in both cranial and caudal endplates. Fracture morphology appeared similar between the control and vertebroplasty groups with a large crack typically extending mediolaterally across the endplate. These substantial cracks were located in the middle and posterior regions of the endplate, and occasionally secondary cracks away from the main crack were observed.
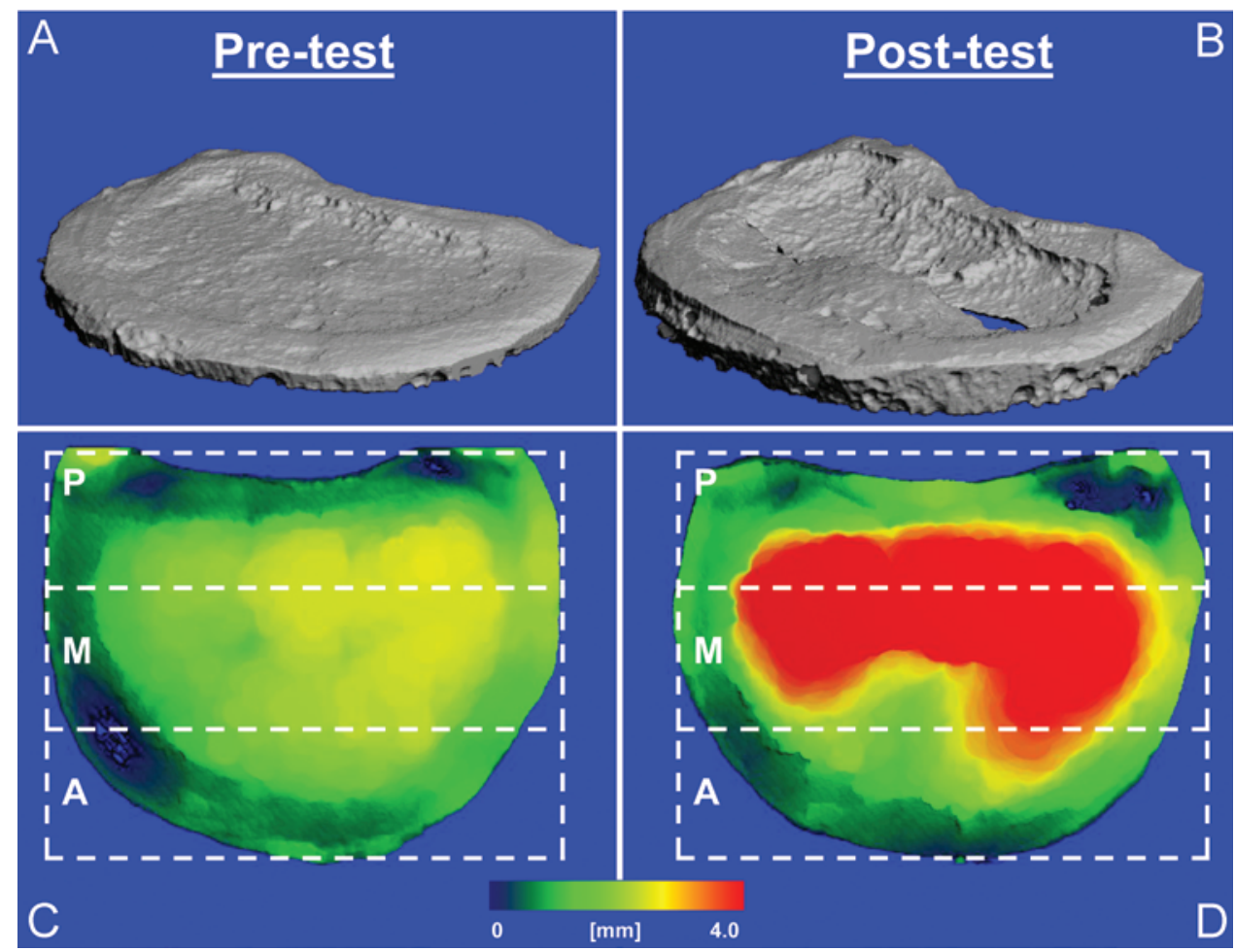

FIG. 2. Subsidence was calculated from micro-CT images as the difference in pretest depression (A) and posttest depression (B) of the endplate. Subsidence was also spatially compared in 3 regions $(A=$ anterior; $M=$ middle; $P=$ posterior) across the endplate (C and D). Figure is available in color online only. 

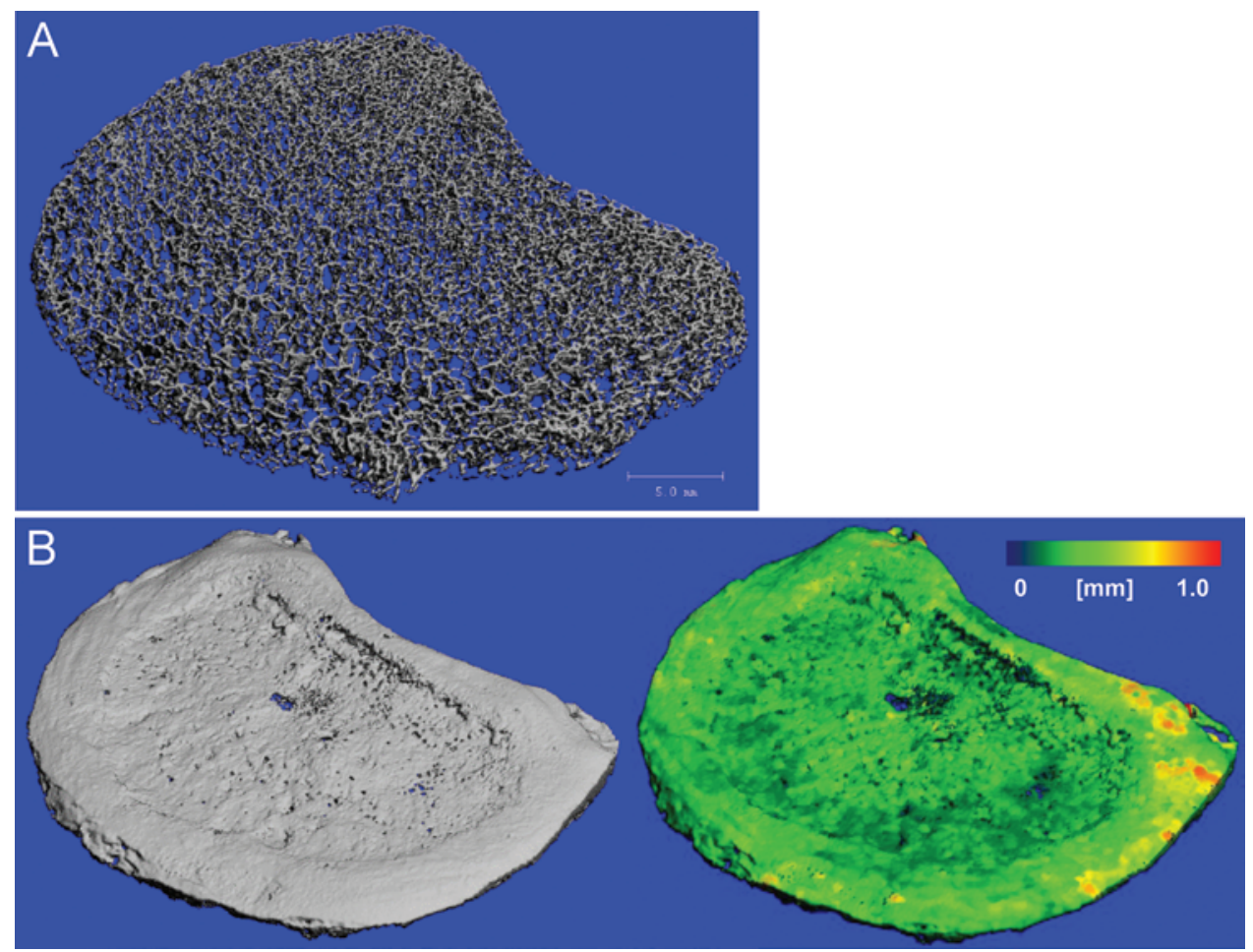

FIG. 3. A: Micro-CT image of 2-mm-thick trabecular bone taken from underneath the endplate was used to calculate the bone volume fraction. B: Micro-CT image of the endplate (left) and thickness map (right). Endplate subsidence was correlated with average endplate thickness and trabecular bone volume fraction. Figure is available in color online only.

For the vertebroplasty group, endplate cracks followed the edge of the underlying bone cement (Fig. 4).

\section{Endplate Subsidence}

The maximum subsidence in $\mathrm{SV}_{\text {cau }}$ endplate for the vertebroplasty group was significantly greater $(\mathrm{p}=0.045)$ than that for the control group (Fig. 5). Maximum subsidence for $\mathrm{TV}_{\text {cra }}, \mathrm{TV}_{\text {cau }}$, and $\mathrm{IV}_{\text {cra }}$ endplates in the vertebroplasty group were on average greater; however, there was substantial variability within each location leading to nonsignificant differences $(\mathrm{p}<0.35)$. The greatest subsidence occurred in the $\mathrm{TV}_{\text {cra }}$ endplates for both vertebroplasty and control groups (Table 2). For the control group, subsidence in the $\mathrm{TV}_{\text {cra }}$ endplate was significantly greater $(\mathrm{p}<0.01)$ when compared with the $\mathrm{SV}_{\text {cau }}, \mathrm{TV}_{\text {cau }}$, and $\mathrm{IV}_{\text {cra }}$ endplates. Due to large standard deviations in the vertebroplasty group, subsidence in the $\mathrm{TV}_{\text {cra }}$ endplate was not significantly different $(p=0.14)$ from that in surrounding endplates. Spatial analysis revealed that endplate subsidence in the vertebroplasty group was higher in the anterior and middle portions of the $\mathrm{SV}_{\text {cau }}$ endplate compared with controls ( $\mathrm{p} \leq 0.09)$ (Fig. 6). In the treated level, there were trends $(p<0.10)$ of increased subsidence in the posterior regions of the $\mathrm{TV}_{\text {cra }}$ and $\mathrm{TV}_{\text {cau }}$ endplates for the vertebroplasty group. No differences in endplate subsidence were observed spatially between the vertebroplasty and control groups in the $I V_{\text {cra }}$ endplate.

\section{Correlation of Subsidence With Endplate Thickness and Trabecular Bone Volume Fraction}

Endplate thickness and trabecular bone volume fraction for the $\mathrm{IV}_{\text {cra }}$ endplate were not calculated for correlation analyses due to low subsidence and lack of differences observed between the vertebroplasty and control groups. For $\mathrm{SV}_{\text {cau }}, \mathrm{TV}_{\text {cra }}$, and $\mathrm{TV}_{\text {cau }}$ endplates, average endplate thicknesses ranged from 0.37 to $0.70 \mathrm{~mm}$ and were not significantly different between groups or vertebral levels. In the $\mathrm{SV}_{\text {cau }}$ endplate, there was no correlation $\left(\mathrm{R}^{2}=1 \%-3 \%\right)$ between subsidence and thickness for either vertebroplasty or control groups. For the treated-level endplates $\left(\mathrm{TV}_{\text {cra }}\right.$ and $\mathrm{TV}_{\text {cau }}$ ), there were negative correlations between subsidence and endplate thickness for both the control $\left(\mathrm{R}^{2}=\right.$ $37 \%-44 \%)$ and vertebroplasty $\left(\mathrm{R}^{2}=3 \%-22 \%\right)$ groups, with nonsignificant differences between groups (Fig. 7). Trabecular bone volume fraction underneath the endplate ranged from $6.4 \%$ to $7.8 \%$ and also was not different between groups or vertebral levels. For treated level endplates, adding the trabecular bone volume fraction as a covariate in the regression analysis slightly improved correlation for the control group $\left(\mathrm{R}^{2}=37 \%-53 \%\right)$ and increased correlation in the vertebroplasty group $\left(\mathrm{R}^{2}=37 \%-62 \%\right)$. The addition of trabecular bone volume fraction in the $\mathrm{SV}_{\text {cau }}$ endplate substantially improved correlation $\left(\mathrm{R}^{2}=54 \%\right)$ for the control group, but not in the vertebroplasty group $\left(\mathrm{R}^{2}\right.$ $=3 \%)$, leading to nearly significant $(\mathrm{p}=0.09)$ differences between treatment groups (data not shown).

\section{Discussion}

It is well accepted that vertebral endplates represent biomechanical weak links in the lumbar spine as evidenced by a high frequency of endplate fractures in patients who suffer VCFs. ${ }^{18,20,35}$ However, it is unclear whether endplate 

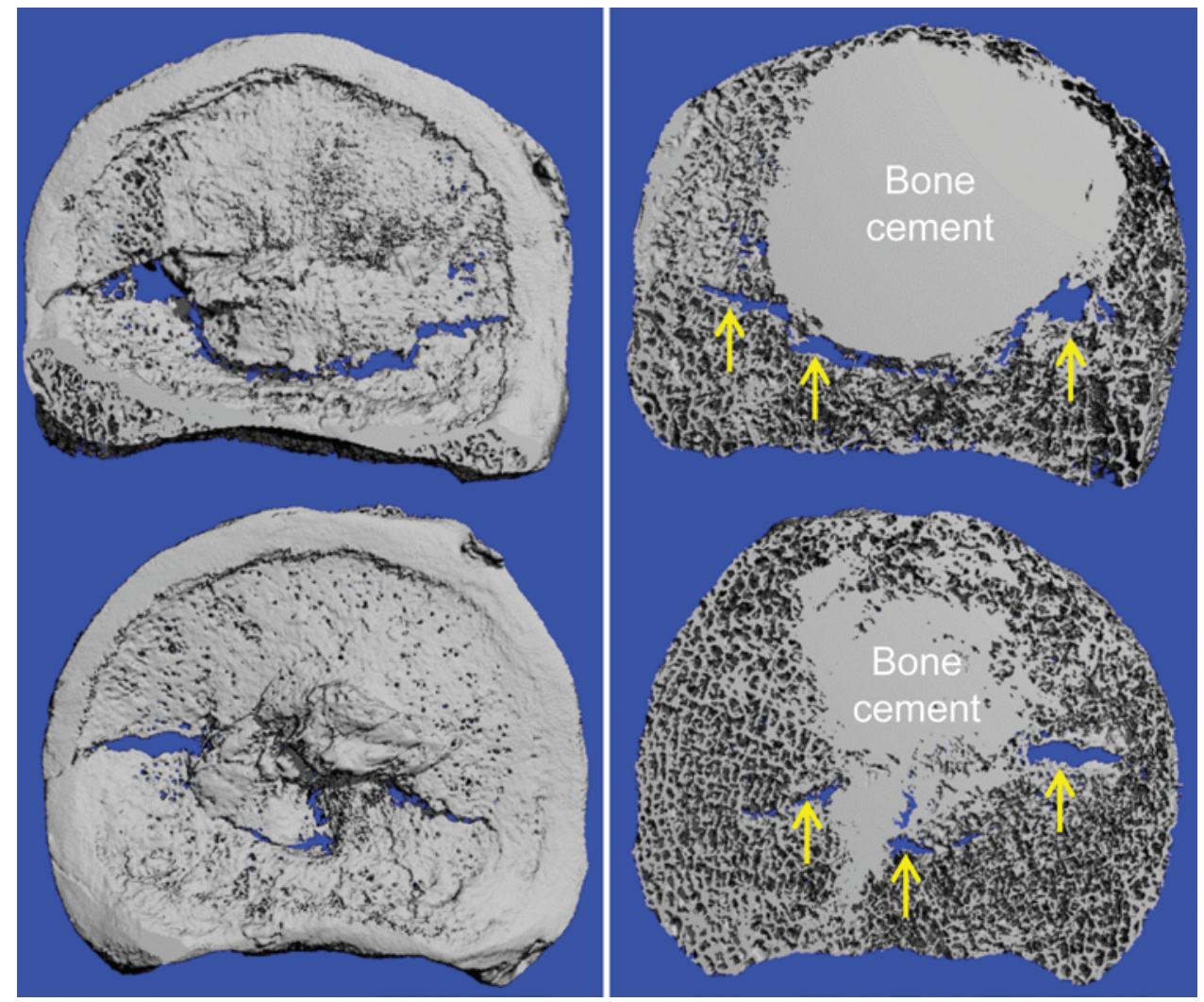

FIG. 4. Cranial endplates in the treated level of the vertebroplasty group exhibited a high rate of fractures after mechanical testing (left). When observed from underneath the endplate (right), the cracks extended along the edge of the bone cement-trabecular bone interface (arrows). Figure is available in color online only.

disruption is exacerbated by vertebroplasty and if the magnitude of subsidence is dependent on endplate thickness and the underlying trabecular bone. In this study, we developed techniques to understand whether vertebroplasty increases subsidence in endplates surrounding the treated level. Our results indicated that vertebroplasty increased endplate subsidence in the superior adjacent and treated

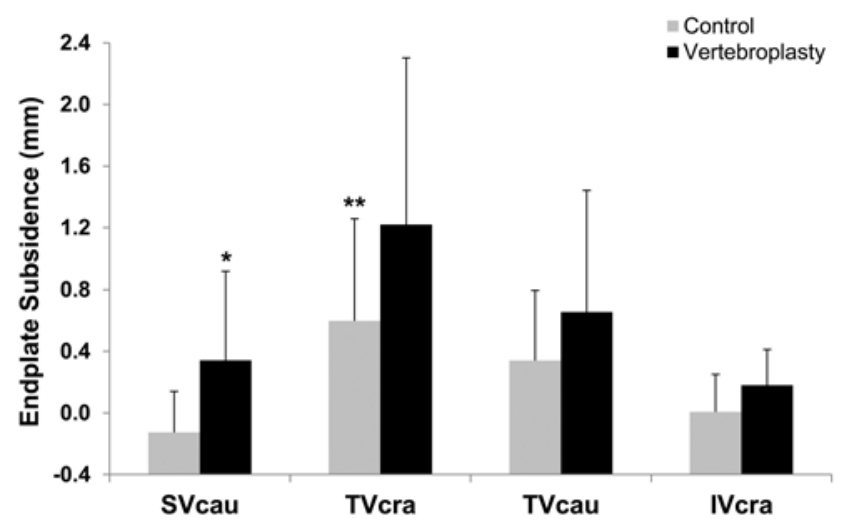

FIG. 5. Subsidence in the $\mathrm{SV}_{\text {cau, }}, \mathrm{TV}_{\text {cra }}, T \mathrm{~V}_{\text {cau }}$, and $\mathrm{IV}_{\text {cra }}$ endplates. In the vertebroplasty group, subsidence in the $\mathrm{SV}_{\text {cau }}$ endplate was significantly higher than that in the control group $\left({ }^{*} p<0.05\right)$. In the control group, the subsidence of the $T V_{\text {cra }}$ endplate was significantly greater $\left({ }^{* *} p<0.01\right)$ when compared with the $\mathrm{SV}_{\text {cau }}, \mathrm{TV}_{\text {cau }}$, and IV $\mathrm{I}_{\text {cra }}$ endplates. There was no significant difference between groups regarding subsidence in the $T V_{\text {cra, }}$ $\mathrm{TV}_{\text {cau }}$, and $\mathrm{IV}_{\text {cra }}$ endplates $(\mathrm{p}>0.16)$. Bars represent the mean values; whiskers represent the SD. levels of injected vertebrae when compared with nonaugmented controls. Our findings are in contrast to those of Hulme and colleagues who found that quasi-static mechanical loading did not increase endplate subsidence in adjacent vertebrae and significantly reduced endplate subsidence in the treated level postvertebroplasty. ${ }^{19}$ The differences observed between studies may be due to the manner in which specimens were mechanically tested (i.e., static vs dynamic). In this study, longer (5-level) spine sections were tested under physiologically relevant cyclic loading conditions that simulated up to 2 months of brisk walking. This dynamic loading profile incorporated the viscoelastic behavior of IVDs and VBs as load was transferred through the spinal column. Furthermore, micro-CT imaging of specimens was conducted at a higher resolution ( 0.05 vs $0.08 \mathrm{~mm}$ ), allowing for decreased artifacts (e.g., partial volume effects) and more precise quantification of endplate deformation.

Spatial analysis determined that increased subsidence occurred in the anterior regions of the $\mathrm{SV}_{\text {cau }}$ endplate and in the posterior regions of the treated-level endplates $\left(\mathrm{TV}_{\text {cra }}\right.$ and $\mathrm{TV}_{\text {cau }}$ ). We suspect that placement of bone cement in the anterior half of the treated vertebra altered local biomechanics to disrupt surrounding endplates. For the treated level, bone cement prevented endplate deformation in the anterior region, but allowed for higher compliance in the posterior regions of the $\mathrm{TV}_{\text {cra }}$ and $\mathrm{TV}_{\text {cau }}$ endplates where bone cement was absent, resulting in increased subsidence posteriorly. Since bone cement in the anterior region pre- 
TABLE 2. Subsidence for the $\mathrm{SV}_{\text {cau }}, \mathrm{TV}_{\text {cra }}, \mathrm{TV}_{\text {cau }}$, and $\mathrm{IV}_{\text {cra }}$ endplates for control and vertebroplasty groups

\begin{tabular}{lcccc}
\hline & \multicolumn{4}{c}{ Mean Subsidence \pm SD $(\mathrm{mm})$} \\
\cline { 2 - 5 } Group & $\mathrm{SV}_{\text {cau }}$ & $\mathrm{TV}_{\text {cra }}$ & $\mathrm{TV}_{\text {cau }}$ & $\mathrm{IV}_{\text {cra }}$ \\
\hline Control & $-0.13 \pm 0.27$ & $0.60 \pm 0.66$ & $0.34 \pm 0.45$ & $0.01 \pm 0.24$ \\
\hline Vertebroplasty & $0.34 \pm 0.58$ & $1.22 \pm 1.08$ & $0.66 \pm 0.79$ & $0.18 \pm 0.23$ \\
\hline p value & 0.045 & 0.186 & 0.348 & 0.166 \\
\hline
\end{tabular}

vented deformation of the $\mathrm{TV}_{\mathrm{cra}}$ endplate, increased stresses may have developed in the superior adjacent IVD and thus transferred stresses to the anterior portion of the $\mathrm{SV}_{\text {cau }}$ endplate. Our previous study supports this hypothesis as 2- and 4-fold higher compression in the superior IVD and $\mathrm{VB}$, respectively, was found after vertebroplasty. ${ }^{33}$ Interestingly, endplate flattening (i.e., negative subsidence values) occurred in $75 \%$ of $\mathrm{SV}_{\text {cau }}$ endplates that did not undergo vertebroplasty. This was particularly evident in middle and posterior regions of the endplate. It is unclear why this phenomenon would have occurred, but endplate flattening values were small $(\sim 0.1 \mathrm{~mm})$ and may be within the error of the quantification technique.

The highest endplate deformations occurred in the treated cranial endplate, which corresponded well to the endplate fractures that were observed after mechanical testing in both groups. In fact, subsidence in fractured
$\mathrm{TV}_{\text {cra }}$ endplates $(1.18 \mathrm{~mm})$ for the control group was almost 5 times greater compared with those that did not fracture $(0.25 \mathrm{~mm})$. This result was even more pronounced in the vertebroplasty group where the average subsidence in fractured $\mathrm{TV}_{\text {cra }}$ endplates $(1.64 \mathrm{~mm})$ was substantially higher compared with nonfractured endplates $(-0.03 \mathrm{~mm})$. The higher rate of fractures in the treated level for vertebroplasty specimens was surprising, considering that stiff polymethylmethacrylate bone cement was expected to provide mechanical stability to the VB, preventing deformation in the endplates. Examination of coronal sections of the T12-L2 spine in pre- and posttest micro-CT images revealed subsidence in unsupported regions around the bone cement, where stress concentrations may occur locally from stiffness mismatch between the trabecular bone and bone cement (Fig. 8). This is important clinically as endplate-endplate cement augmentation may pre-
A
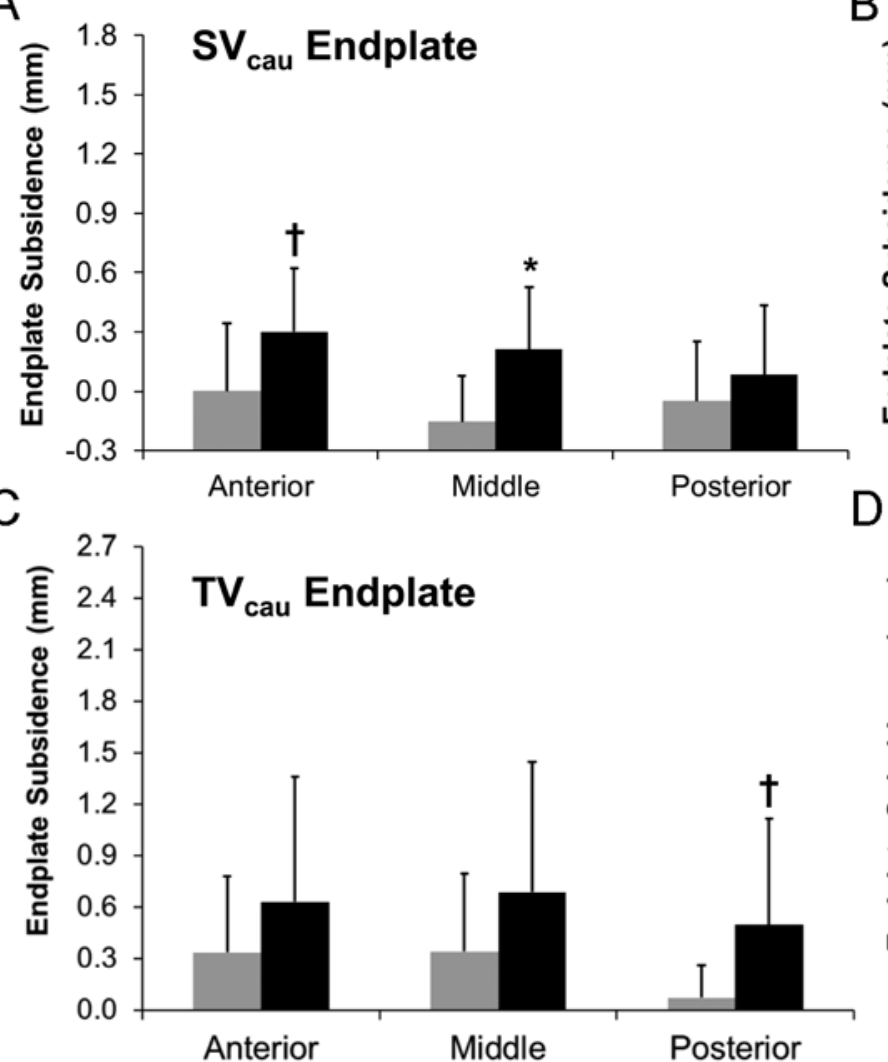

B
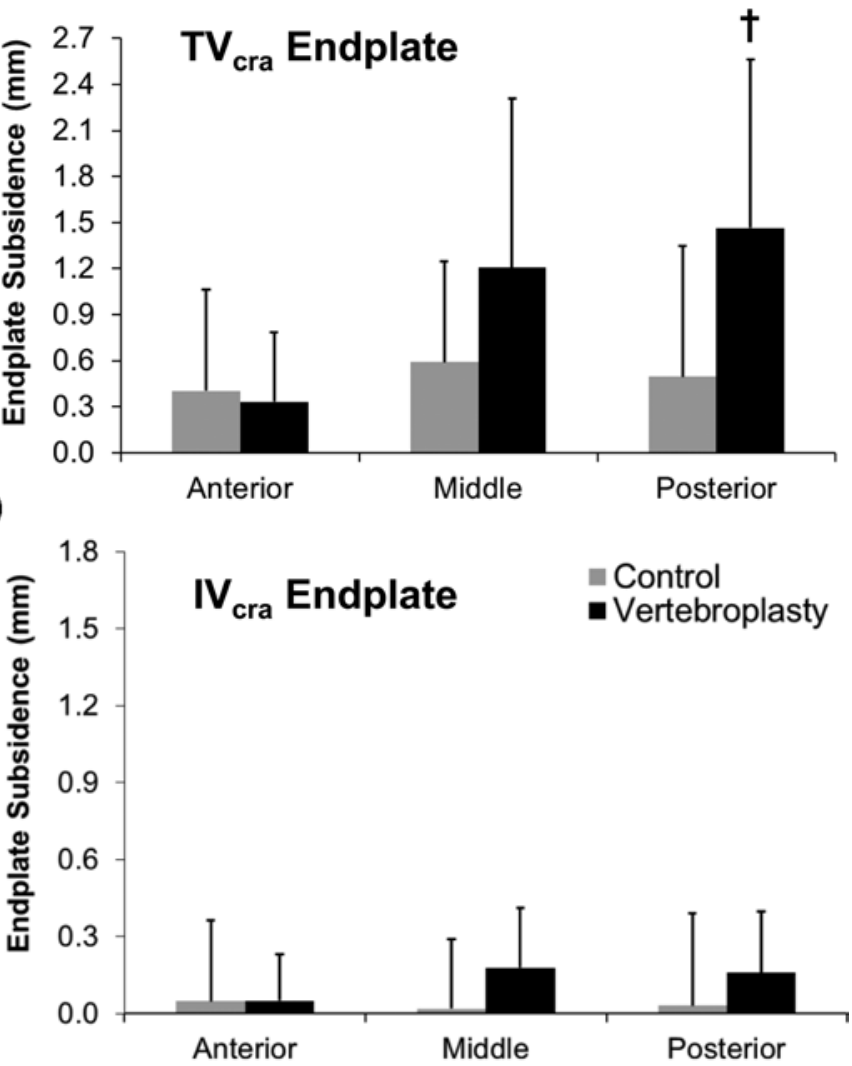

FIG. 6. Spatial analysis of subsidence in surrounding endplates. The anterior $(t p=0.09)$ and middle $\left({ }^{*} p=0.02\right)$ regions of the $S_{\text {cau }}$ endplate (A) had greater subsidence in vertebroplasty samples. The posterior regions of the $T_{\text {cra }}(B)$ and $T_{\text {cau }}(C)$ endplates subsided more when compared with controls $(\dagger p<0.10)$. No significant differences were observed in the IV cra $_{\text {endplate }}(D, p>$ 0.22). Bars represent the mean values; whiskers represent the SD. 

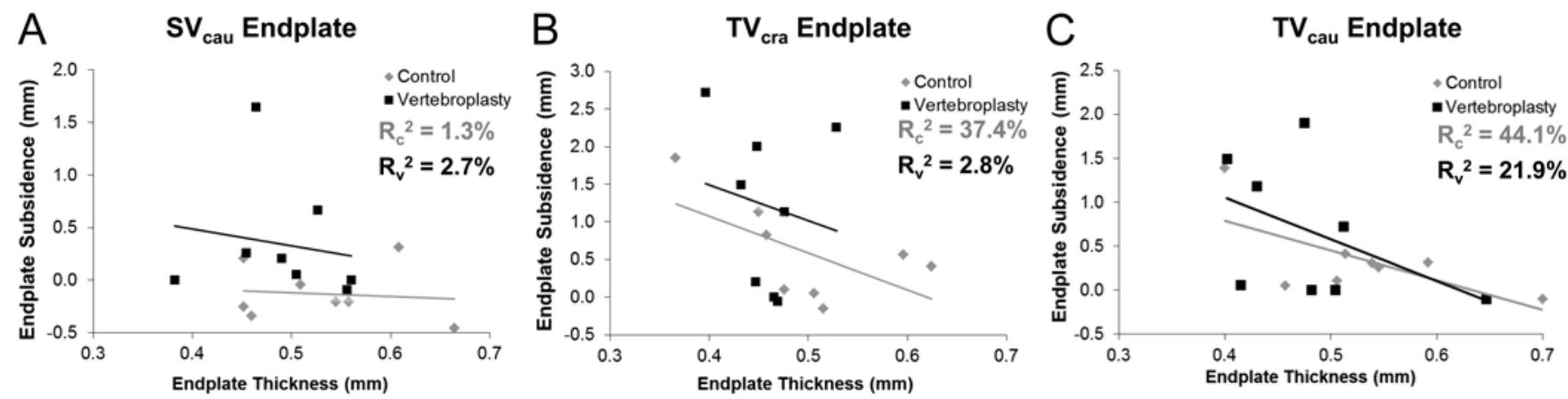

FIG. 7. Endplate subsidence versus endplate thickness for surrounding endplates. Regression analysis for the $\mathrm{SV}_{\text {cau }}$ endplate (A) determined that subsidence was not correlated with thickness in either the vertebroplasty or control group. Moderate correlations $\left(R^{2}=37 \%-44 \%\right)$ were observed in the $\mathrm{TV}_{\text {cra }}(\mathrm{B})$ and $\mathrm{TV}_{\text {cau }}(\mathrm{C})$ endplates in the control group. However, no significant differences were observed between the vertebroplasty and control groups $(p>0.29)$.

vent deformation in supported regions, but it creates stress concentrations in neighboring unsupported regions and increases load transfer to adjacent levels.

Clinical studies have differed in terms of the predominant location (i.e., superior/inferior) of adjacent vertebral fractures postvertebroplasty, with some studies finding an equal distribution of adjacent fractures and others finding a higher fracture incidence in the superior adjacent vertebrae. ${ }^{1,14,29,30}$ For endplates specifically, Trout and colleagues found that the caudal endplate of the superior adjacent VB had significantly more fractures than any other endplate. ${ }^{45}$ Our results are in good agreement with this study, as we observed an approximately 2 -fold increase in endplate deformation for the $\mathrm{SV}_{\text {cau }}$ endplate compared with the $\mathrm{IV}_{\text {cra }}$ endplate in the vertebroplasty group. In the control group, there was no difference in endplate disruption between $\mathrm{SV}_{\text {cau }}$ and $\mathrm{IV}_{\text {cra }}$ endplates, suggesting that injection of bone cement alters mechanics locally in the caudal endplate of the superior adjacent vertebra. Since $\mathrm{SV}_{\text {cau }}$ endplates typically have smaller footprints than $\mathrm{IV}_{\text {cra }}$ endplates, we hypothesize that these stresses may preferentially increase subsidence in the $\mathrm{SV}_{\text {cau }}$ endplate.

From a biomechanics perspective, endplate thickness and trabecular bone volume fraction are important fac- tors in providing the necessary amount of support and "scaffolding" to prevent subsidence. This is evident in the elderly where cortical thinning and reduced trabecular bone quantity and quality weaken the vertebrae leading to osteoporotic fractures in the spine. In fact, Hulme and colleagues found a correlation $\left(\mathrm{R}^{2}=34 \%\right)$ between endplate subsidence and bone volume fraction in the anterior region of nonaugmented vertebrae. ${ }^{19}$ For vertebroplasty specifically, however, it is unclear whether bone volume fraction would influence endplate subsidence, particularly since bone cement resides in marrow spaces between trabeculae, altering the porous nature of trabecular bone. Our findings indicated that endplate thickness was moderately correlated with subsidence for endplates in the control group and less correlated in the vertebroplasty group. The addition of trabecular bone volume fraction as a covariate generally increased correlation with subsidence; however, trabecular bone volume fraction appeared to be particularly important in the superior adjacent vertebra where a significant difference between vertebroplasty and control groups was almost observed. We speculate that more pronounced differences between groups might be found if a broader patient population was used in this study. One limitation in this study was that a specific patient popula-

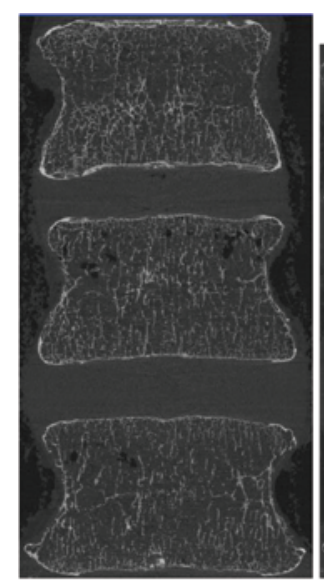

Pre-test

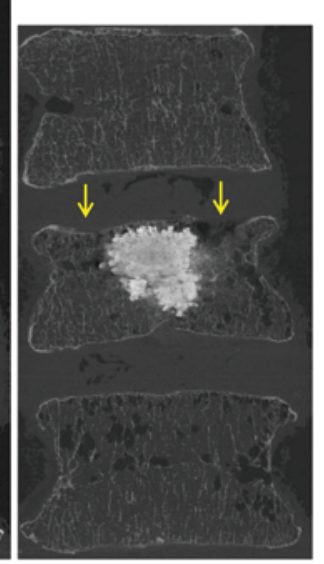

Post-test

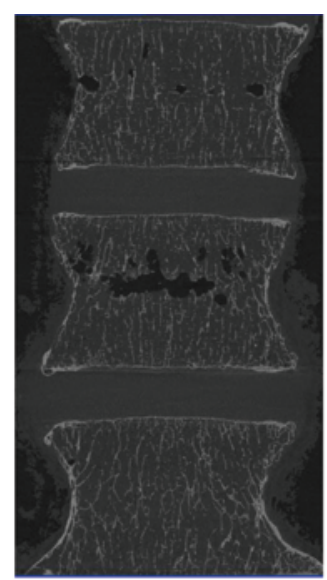

Pre-test

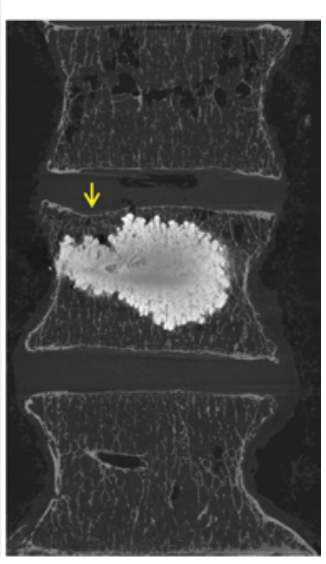

Post-test

FIG. 8. Coronal radiographs of the T12-L2 spine complex before and after mechanical testing. In the vertebroplasty-treated spines, subsidence was localized in unsupported regions surrounding the bone cement (arrows). These disruptions in the endplate are also associated with loss of vertebral and IVD height. Figure is available in color online only. 
tion (i.e., elderly Caucasian females) was used, resulting in a narrow range of trabecular bone volume fraction $(6 \%-$ $7 \%$ ). A more diverse patient population would provide a wider range of bone volume fraction values and may elucidate the importance of bone volume fraction in endplate subsidence. In addition, a more localized analysis of endplate thickness and trabecular bone volume fraction may be necessary to establish stronger correlations to endplate subsidence. It is also plausible that other factors such as endplate density or quality of the IVD may help explain the subsidence observed in this study.

\section{Conclusions}

Vertebroplasty performed in elderly female spines may increase the risk for endplate subsidence, especially in the superior adjacent and treated levels of injected vertebrae. These data add experimental evidence to previous finite element studies that demonstrated that vertebroplasty alters load transfer, resulting in increased stresses in adjacent endplates. By simulating walking loads on the lumbar spine for a period of 1-2 months, we observed on average $1.2 \mathrm{~mm}$ of endplate subsidence within the treated level and 0.35 $\mathrm{mm}$ of subsidence in the caudal endplate of the superior adjacent level with vertebroplasty, suggesting that disruption of the endplates after vertebroplasty may be the initial mechanism of adjacent-level fractures. In fact, Figs. 4 and 8 provide visual evidence of this phenomenon of endplate cracking around the bone cement at the treated level, likely due to a stress concentration created at that interface. We suspect that with longer cyclic loading, caudal endplates of the superior adjacent vertebrae would fracture and lead to subsequent compression fractures that have been observed clinically after vertebroplasty. ${ }^{45}$ For osteoporotic women in particular, the high stiffness of PMMA bone cement and spatial distribution within the VB may be significant factors in the increased risk of adjacent-level fractures. Previous biomechanical studies have characterized how decreasing bone cement modulus and changing the distribution of bone cement affects vertebral stiffness. ${ }^{5,28}$ However, fatigue studies are needed to elucidate whether endplate subsidence and damage are minimized in the treated and adjacent levels with these options. Nevertheless, better clinical outcomes may be achieved by investigating whether new treatment strategies can prevent stress concentrations from developing at the endplates of the treated level.

\section{Acknowledgments}

We thank Valerie Elliott and David Baer, $\mathrm{PhD}$, at the United States Department of Agriculture for aid with DEXA measurements; Scott Miller, PhD, for statistical analysis support; Anton Dmitriev, $\mathrm{PhD}$, and William Pritchard, $\mathrm{MD}, \mathrm{PhD}$, for assistance with vertebroplasty procedures; and Katarina Radmanovic, Miranda Hagen, and Raheem Rashid for micro-CT analysis.

\section{References}

1. Anselmetti GC, Manca A, Hirsch J, Montemurro F, Isaia G, Osella G, et al: Percutaneous vertebroplasty in osteoporotic patients: an institutional experience of 1,634 patients with long-term follow-up. J Vasc Interv Radiol 22:1714-1720, 2011

2. Baroud G, Bohner M: Biomechanical impact of vertebroplas- ty. Postoperative biomechanics of vertebroplasty. Joint Bone Spine 73:144-150, 2006

3. Baroud G, Heini P, Nemes J, Bohner M, Ferguson S, Steffen T: Biomechanical explanation of adjacent fractures following vertebroplasty. Radiology 229:606-608, 2003 (Letter)

4. Baroud G, Nemes J, Heini P, Steffen T: Load shift of the intervertebral disc after a vertebroplasty: a finite-element study. Eur Spine J 12:421-426, 2003

5. Boger A, Heini P, Windolf M, Schneider E: Adjacent vertebral failure after vertebroplasty: a biomechanical study of low-modulus PMMA cement. Eur Spine J 16:2118-2125, 2007

6. Buchbinder R, Osborne RH, Ebeling PR, Wark JD, Mitchell P, Wriedt C, et al: A randomized trial of vertebroplasty for painful osteoporotic vertebral fractures. N Engl J Med 361:557-568, 2009

7. Buchbinder R, Osborne RH, Kallmes D: Vertebroplasty appears no better than placebo for painful osteoporotic spinal fractures, and has potential to cause harm. Med J Aust 191:476-477, 2009

8. Cappozzo A: Compressive loads in the lumbar vertebral column during normal level walking. J Orthop Res 1:292-301, 1984

9. Chosa K, Naito A, Awai K: Newly developed compression fractures after percutaneous vertebroplasty: comparison with conservative treatment. Jpn J Radiol 29:335-341, 2011

10. Dean JR, Ison KT, Gishen P: The strengthening effect of percutaneous vertebroplasty. Clin Radiol 55:471-476, 2000

11. Eswaran SK, Gupta A, Adams MF, Keaveny TM: Cortical and trabecular load sharing in the human vertebral body. $\mathbf{J}$ Bone Miner Res 21:307-314, 2006

12. Fisher CG, Vaccaro AR: The highest level of evidence in a high impact journal: is this the final verdict? Spine (Phila Pa 1976) 35:E676-E677, 2010

13. Fisher CG, Vaccaro AR, Thomas KC, Angevine PD, Mulpuri K, Patel AA, et al: Evidence-based recommendations for spine surgery. Spine (Phila Pa 1976) 35:E678-E686, 2010

14. Han IH, Chin DK, Kuh SU, Kim KS, Jin BH, Yoon YS, et al: Magnetic resonance imaging findings of subsequent fractures after vertebroplasty. Neurosurgery 64:740-745, 2009

15. Hildebrand T, Laib A, Müller R, Dequeker J, Rüegsegger P: Direct three-dimensional morphometric analysis of human cancellous bone: microstructural data from spine, femur, iliac crest, and calcaneus. J Bone Miner Res 14:1167-1174, 1999

16. Hildebrand T, Rüegsegger P: A new method for the modelindependent assessment of thickness in three-dimensional images. J Microsc 185:67-75, 1997

17. Hirsch JA, Hirsch AE, Zoarski GH, Brook AL, Stone JA, Heck DV, et al: Social responsibility in medical reporting. J Neurointerv Surg 2:217-218, 2010

18. Holmes AD, Hukins DW, Freemont AJ: End-plate displacement during compression of lumbar vertebra-disc-vertebra segments and the mechanism of failure. Spine (Phila Pa 1976) 18:128-135, 1993

19. Hulme PA, Boyd SK, Heini PF, Ferguson SJ: Differences in endplate deformation of the adjacent and augmented vertebra following cement augmentation. Eur Spine J 18:614-623, 2009

20. Jiang G, Luo J, Pollintine P, Dolan P, Adams MA, Eastell R: Vertebral fractures in the elderly may not always be "osteoporotic." Bone 47:111-116, 2010

21. Kallmes DF, Comstock BA, Heagerty PJ, Turner JA, Wilson DJ, Diamond TH, et al: A randomized trial of vertebroplasty for osteoporotic spinal fractures. N Engl J Med 361:569579,2009

22. Kaufmann TJ, Trout AT, Kallmes DF: The effects of cement volume on clinical outcomes of percutaneous vertebroplasty. AJNR Am J Neuroradiol 27:1933-1937, 2006

23. Kettler A, Schmoelz W, Shezifi Y, Ohana N, Ben-Arye 
A, Claes L, et al: Biomechanical performance of the new BeadEx implant in the treatment of osteoporotic vertebral body compression fractures: restoration and maintenance of height and stability. Clin Biomech (Bristol, Avon) 21:676682,2006

24. Kim DJ, Kim TW, Park KH, Chi MP, Kim JO: The proper volume and distribution of cement augmentation on percutaneous vertebroplasty. J Korean Neurosurg Soc 48:125-128, 2010

25. Kim SH, Kang HS, Choi JA, Ahn JM: Risk factors of new compression fractures in adjacent vertebrae after percutaneous vertebroplasty. Acta Radiol 45:440-445, 2004

26. Kinoshita T, Ebara S, Kamimura M, Tateiwa Y, Itoh H, Yuzawa Y, et al: Nontraumatic lumbar vertebral compression fracture as a risk factor for femoral neck fractures in involutional osteoporotic patients. J Bone Miner Metab 17:201-205, 1999

27. Klazen CA, Lohle PN, de Vries J, Jansen FH, Tielbeek AV, Blonk MC, et al: Vertebroplasty versus conservative treatment in acute osteoporotic vertebral compression fractures (Vertos II): an open-label randomised trial. Lancet 376:1085-1092, 2010

28. Liebschner MAK, Rosenberg WS, Keaveny TM: Effects of bone cement volume and distribution on vertebral stiffness after vertebroplasty. Spine (Phila Pa 1976) 26:1547-1554, 2001

29. Lin EP, Ekholm S, Hiwatashi A, Westesson PL: Vertebroplasty: cement leakage into the disc increases the risk of new fracture of adjacent vertebral body. AJNR Am J Neuroradiol 25:175-180, 2004

30. Mazzantini M, Carpeggiani P, d'Ascanio A, Bombardieri S, Di Munno O: Long-term prospective study of osteoporotic patients treated with percutaneous vertebroplasty after fragility fractures. Osteoporos Int 22:1599-1607, 2011

31. Melton LJ III: Epidemiology of spinal osteoporosis. Spine (Phila Pa 1976) 22 (24 Suppl):2S-11S, 1997

32. Molloy S, Mathis JM, Belkoff SM: The effect of vertebral body percentage fill on mechanical behavior during percutaneous vertebroplasty. Spine (Phila Pa 1976) 28:1549-1554, 2003

33. Nagaraja S, Awada HK, Dreher ML, Gupta S, Miller SW: Vertebroplasty increases compression of adjacent IVDs and vertebrae in osteoporotic spines. Spine J 13:1872-1880, 2013

34. Oakland RJ, Furtado NR, Wilcox RK, Timothy J, Hall RM: Preliminary biomechanical evaluation of prophylactic vertebral reinforcement adjacent to vertebroplasty under cyclic loading. Spine J 9:174-181, 2009

35. Ortiz AO, Bordia R: Injury to the vertebral endplate-disk complex associated with osteoporotic vertebral compression fractures. AJNR Am J Neuroradiol 32:115-120, 2011

36. Polikeit A, Nolte LP, Ferguson SJ: The effect of cement augmentation on the load transfer in an osteoporotic functional spinal unit: finite-element analysis. Spine (Phila Pa 1976) 28:991-996, 2003
37. Riggs BL, Melton LJ III: The worldwide problem of osteoporosis: insights afforded by epidemiology. Bone 17 (5 Suppl):505S-511S, 1995

38. Rüegsegger P, Koller B, Müller R: A microtomographic system for the nondestructive evaluation of bone architecture. Calcif Tissue Int 58:24-29, 1996

39. Samelson EJ, Hannan MT, Zhang Y, Genant HK, Felson DT, Kiel DP: Incidence and risk factors for vertebral fracture in women and men: 25-year follow-up results from the population-based Framingham study. J Bone Miner Res 21:1207-1214, 2006

40. Stock H, Schneider A, Strauss E: Osteoporosis: a disease in men. Clin Orthop Relat Res (425):143-151, 2004

41. Sun YC, Teng MM, Yuan WS, Luo CB, Chang FC, Lirng JF, et al: Risk of post-vertebroplasty fracture in adjacent vertebral bodies appears correlated with the morphologic extent of bone cement. J Chin Med Assoc 74:357-362, 2011

42. Thillainadesan J, Schlaphoff G, Gibson KA, Hassett GM, McNeil HP: Long-term outcomes of vertebroplasty for osteoporotic compression fractures. J Med Imaging Radiat Oncol 54:307-314, 2010

43. Trout AT, Kallmes DF: Does vertebroplasty cause incident vertebral fractures? A review of available data. AJNR Am J Neuroradiol 27:1397-1403, 2006

44. Trout AT, Kallmes DF, Kaufmann TJ: New fractures after vertebroplasty: adjacent fractures occur significantly sooner. AJNR Am J Neuroradiol 27:217-223, 2006

45. Trout AT, Kallmes DF, Layton KF, Thielen KR, Hentz JG: Vertebral endplate fractures: an indicator of the abnormal forces generated in the spine after vertebroplasty. $\mathbf{J}$ Bone Miner Res 21:1797-1802, 2006

46. Wilke HJ, Jungkunz B, Wenger K, Claes LE: Spinal segment ranage of motion as a function of in vitro test conditions: effects of exposure period, accumulated cycles, angular-deformation rate, and moisture condition. Anat Rec 251:15-19, 1998

\section{Author Contributions}

Conception and design: Nagaraja, Dreher. Acquisition of data: Nagaraja, Awada, Bouck, Gupta. Analysis and interpretation of data: all authors. Drafting the article: Nagaraja. Critically revising the article: all authors. Reviewed submitted version of manuscript: all authors. Approved the final version of the manuscript on behalf of all authors: Nagaraja. Statistical analysis: Nagaraja. Study supervision: Nagaraja, Dreher.

\section{Correspondence}

Srinidhi Nagaraja, U.S. Food and Drug Administration, Center for Devices and Radiological Health, 10903 New Hampshire Ave., Bldg. 62, Rm. 2210, Silver Spring, MD 20993-0002. email: srinidhi.nagaraja@fda.hhs.gov. 